\title{
Experimental determination of the level of damage suffered by rigid PVC pipes under quasi-static impact load
}

\author{
Fokam Bopda Christian ${ }^{1}$, Kenmeugne Bienvenu ${ }^{1}$ \\ Mansouri Khalifa ${ }^{2}$, Tchotang Theodore ${ }^{1}$, Fogue Medard ${ }^{3}$, Meva'a Lucien ${ }^{1}$
}

\author{
${ }^{1}$ Laboratoire de Mécanique des Solides (LMS) - Ecole Nationale Supérieure Polytechnique de Yaoundé, BP 8390, Ya- \\ oundé-Cameroun \\ e-mail: christian.fokam@polytechnique.cm \\ ${ }^{2}$ EcoleNormaleSupérieure de l'Enseignement Technique, Bd Hassan II, Mohammedia Maroc. \\ ${ }^{3}$ Laboratoire d'Ingénierie des Systèmes Industriels et de l'Environnement (LISIE), IUT Fotso Victor de Band- \\ joun,Cameroun. \\ e-mail: bienvenu.kenmeugne@polytechnique.cm,khmansouri@hotmail.com, theodore.tchotang@polytechnique.cm, \\ medard_fog@yahoo.com,jr167_mevaa@yahoo.com
}

\begin{abstract}
This paper presents a approach to determining the level of damage on rigid PVC pipes (polyvinyl chloride), destined for the supply of drinking water, and previously subjected to quasi-static impact. The originality of the work has been to experimentally characterize the level of damage via readily measurable physical quantities obtained under operating conditions. For this purpose, a wide range of experiments were performed. Firstly, trials involving impact with a hemispherical-end hammer weighing 16kg, dropped from a height of between $0-2 \mathrm{~m}$ on portions of rigid PVC pipe. Thereafter, the dimensions of the affected area on the portions of the pipe are measured using a Tridimensional Measuring Machine (TMM). Finally, tensile tests on flat test pieces from around the impacted area of the pipe section were used to determine the postimpact residual mechanical strength. This investigation on post-impact properties allows the definition of the level of damage reached via the unified theory model of Bui Quoc. By analogy to the latter, the damage is expressed as a function of the area of the impacted section.
\end{abstract}

Keywords: Damage, footprint area, tension, impact tests, rigid PVC, amorphous polymer

\section{INTRODUCTION}

Plastic materials occupy a large part of the drinking water supply pipelines due to its easy of installation and relatively low costs. However, in most of the cases of loss of drinking water in the pipes, the failure of the pipe material is often the cause $[1,2]$.

Drinking water supply pipes are often subject to accidental impacts such as pebbles drops, scratches etc., during their installation. It becomes important for engineers to estimate the residual mechanical strength and ability to withstand the applied pressure. For this, an estimate of the level of damage of the material is necessary.

There exists, in literature, different damage models that predict, for a given stress, the level of damage of the material $[3,4,5]$. Most of these models are based on difficultly measurable quantities during operating conditions. This makes the application of the said models difficult. The aim of this work is to propose a simple and fast approach to constructors that will enable them to assess the level of damage of pipes subjected to impact. The first part of this work is devoted to the presentation of experimental devices used (impact machine, three-dimensional measuring machine, tensile testing machine). Subsequently, an analysis and a comparison of the defined damage are presented in the last part of the article.

\section{MATERIALS AND METHODS}

\subsection{Specimen}


Specimens used are tubes made of polyvinyl chloride (rigid PVC), gray in color, according to the standard (NFT 54016). They come from the same casting. The tube's dimensions are: diameter $63 \mathrm{~mm}$ and thickness $4.5 \mathrm{~mm}$ (Figure 1).
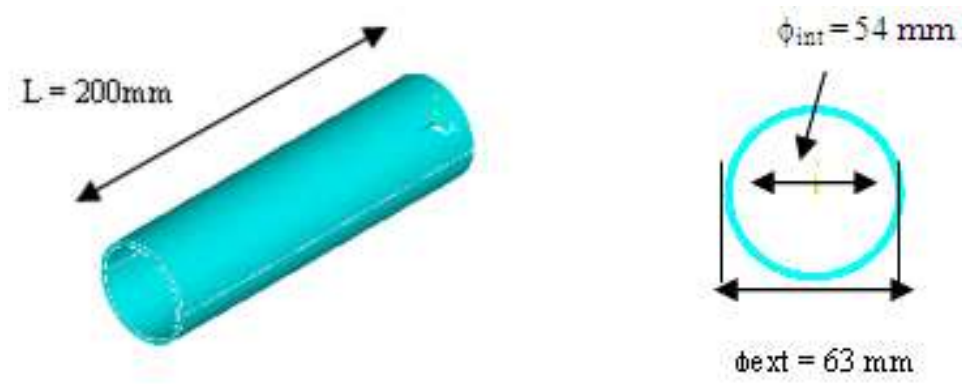

Figure 1: Geometry of tube piece specimen type, used for impact tests (falling weight).

Its mechanical properties are shown in Table 1.

Table1: mechanical properties of rigid PVC

\begin{tabular}{l|l}
\hline PROPERTIES & VALUE \\
\hline Modulus of elasticity & $3200 \mathrm{MPa}$ \\
\hline Breaking strength in tension & $75 \mathrm{MPa}$ \\
\hline Percent elongation & $100 \%$ \\
\hline Breaking strength in compression & $50-75 \mathrm{MPa}$ \\
\hline
\end{tabular}

\subsection{Machinery used}

\section{- Impact Machine}

This device allows the release of a weight called striker from a selected height on a tube piece (Figures 2a and $2 \mathrm{~b}$ ). The tube piece is positioned on a "V"-shaped support. A cylindrical steel rod is inserted into the tube. We used a hemispherical striker (radius $\mathrm{R}=50 \mathrm{~mm}$ ) weighing 16kg (Figure 2c). Released heights are between 0 and $2 \mathrm{~m}$.

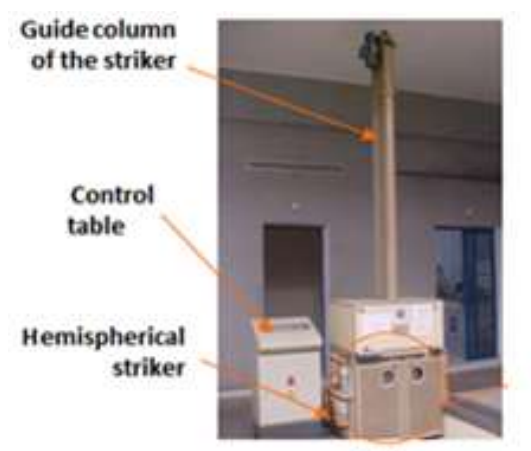

(a)

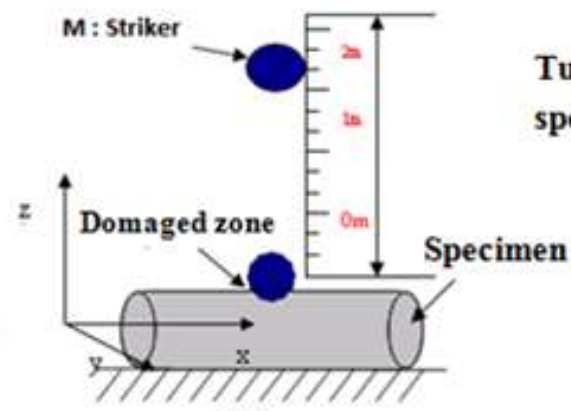

(b)

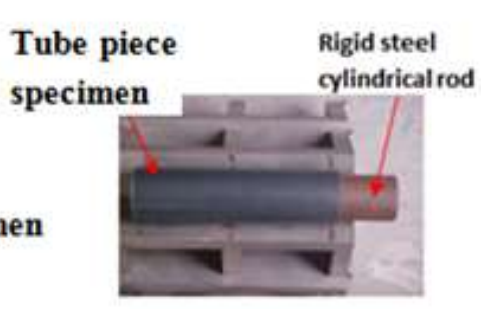

(c)

Figure 2: (a) The impact machine bearing the German brand UTS TESTSYSTEME, (b) Block diagram of the impact machine (c) Positioning the specimen.

The impact of the striker on the tube being tested leaves there on an elliptical footprint (affected or damaged zone shown in Figure 2b). 


\section{- Three-dimensional measuring machines: TMM}

The TMM machine used (Branded Mitutoyo type Euro Strato) has a spherical head probe (Figure 3).
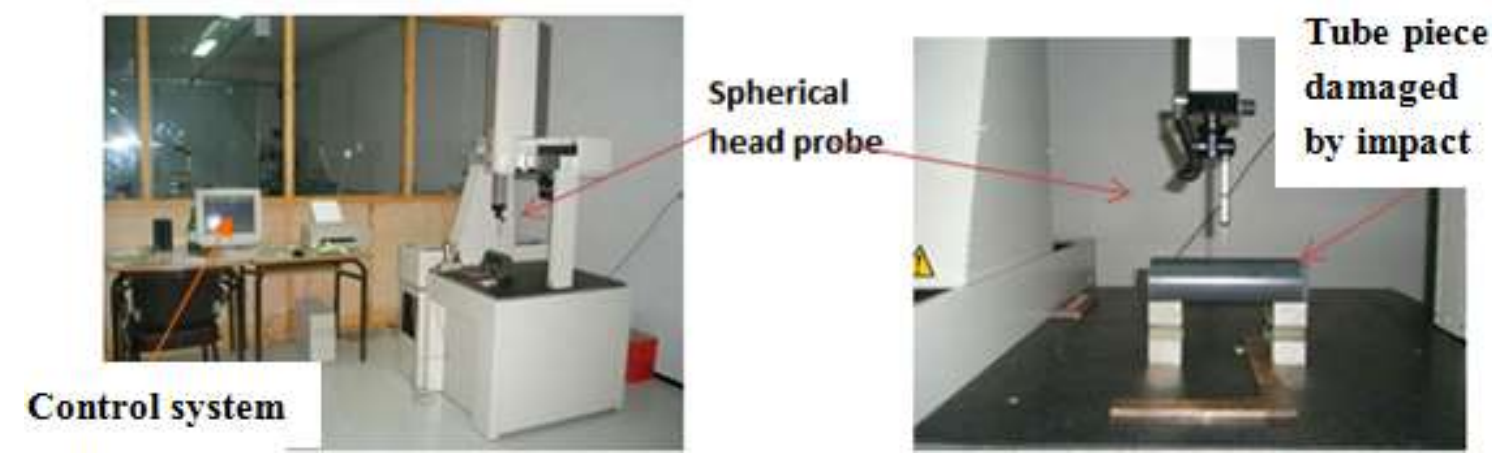

Figure 3: Three-dimensional measuring machine (TMM).

The displacements of the probe of the TMM is programmed according to the direction of the radii of the big and small axis of the elliptical footprint (affected or damaged area) in order to determine the dimensions "a" and "b" (Figure 4). The probe displacement increment in these directions is chosen as $0.5 \mathrm{~mm}$.
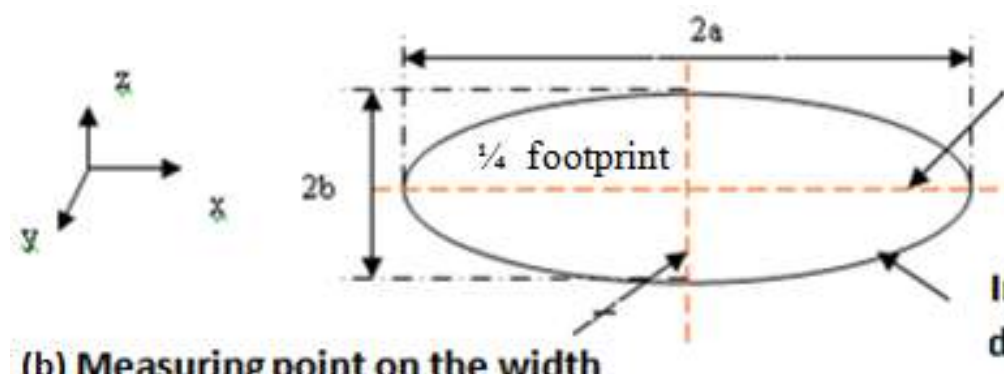

\section{(a) Measuring boint} over the length

\section{(b) Measuring point on the width}

\section{Impacted section: damaged footprint}

Figure 4: Elliptical footprint and desired dimension: (a) The probe contact points along the length, (b) The measuring points (contact) of the sensor along the width with an increment of $0.5 \mathrm{~mm}$.

\section{- Tensile test machine}

Following the impact test, tensile test specimens are taken around the affected area, as presented in Figure 5.

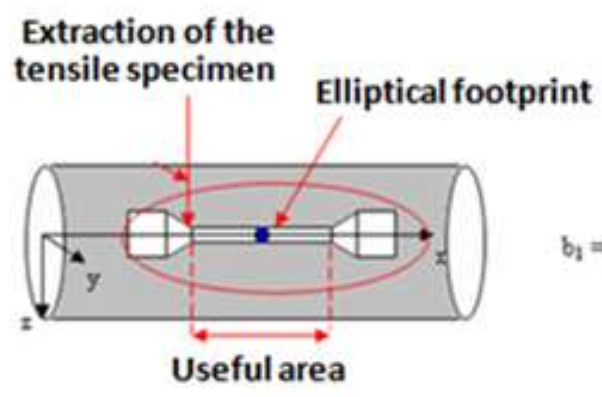

(a)

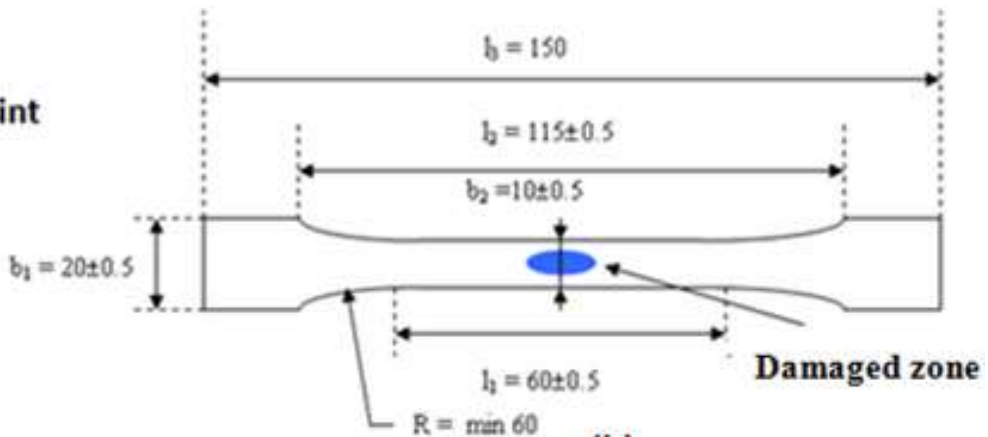

(b)

Figure 5: (a) Machining area of tensile specimens on the tube. (b) Tensile specimen dimensions.

The tensile test machine used bears the mark UTS TESTSYSTEME (Figure 6). Tensile tests are performed there at room temperature, with low deformation speeds of $0.06 \mathrm{~m} . \mathrm{s}^{-1}$, so as to limit the phenomena of self-heating of the material. 


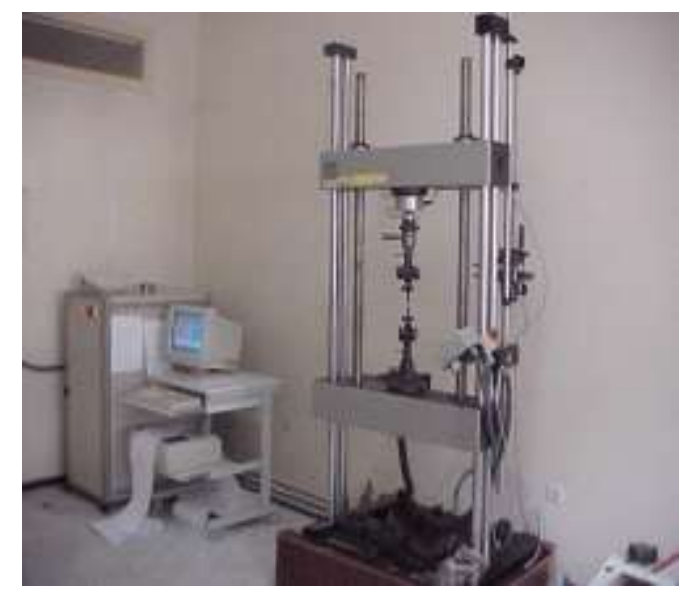

Figure 6: Tensile test machine UTS TESTSYSTEME.

\section{RESULTS AND DISCUSSION}

\subsection{Examination of the measurements taken by the TMM}

It was operated here the discrete series of points obtained from the three-dimensional measuring machine (TMM) with the aim of determining the dimensions of the radii of minor axis and major axes of the impacted area as shown in Figure 4.

Initially all the probed point coordinates obtained with the TMM for the case of a 16kg mass impact test dropped from $1.25 \mathrm{~m}$ (Figure7) are represent in 3D.

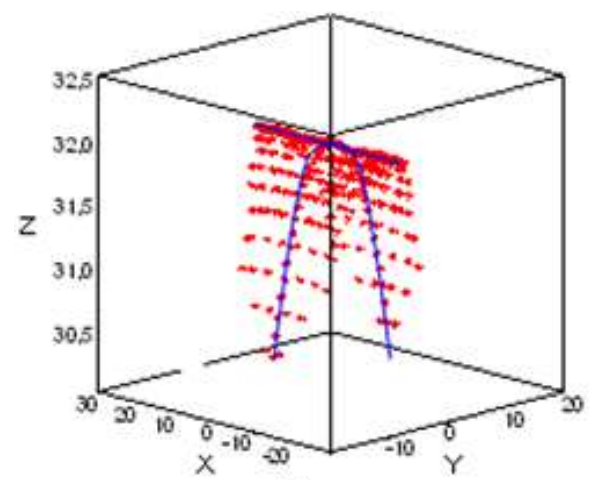

(a)

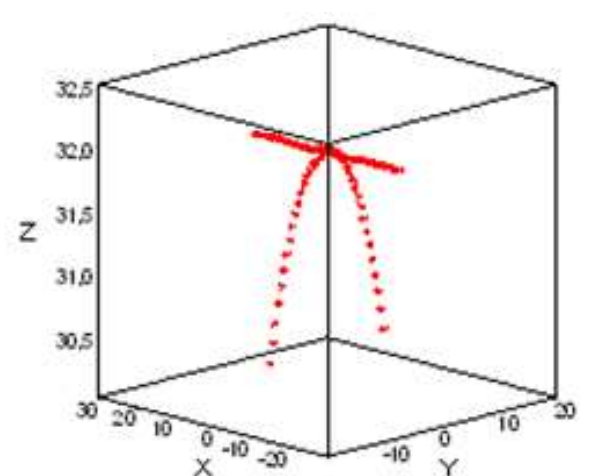

(b)

Figure 7: 3D graphical representation of the series of coordinates obtained by TMM from an impression on an impacted tube; mass $16 \mathrm{~kg}$ / height $1.25 \mathrm{~m}$. (a) For all the measuring points, (b) Representation of the measurement points along the length and width of the tested tube. 


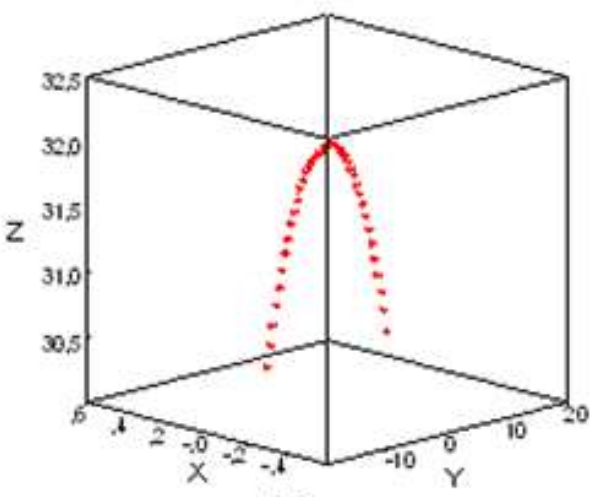

(a)

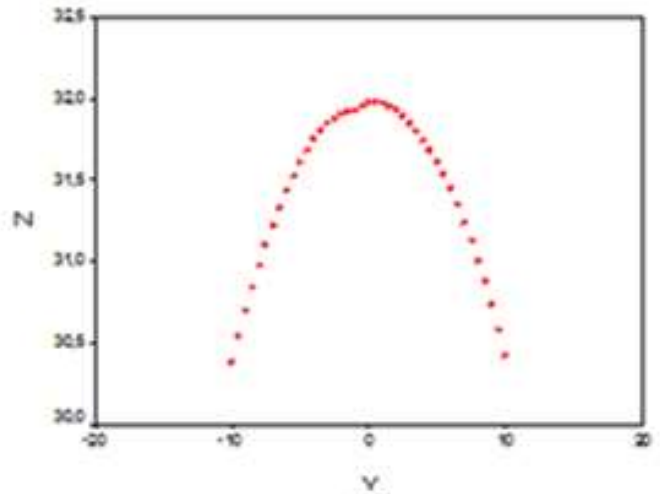

(b)

Figure 8: Graphical representation of points probed only on the width of the footprint with $x=0$, (a) in 3D and (b) in 2D.

The two-dimensional representation allows easier determination of the impacted area (dimensions "a" and "b") by observing the variation in height between the boundaries of the area affected by the impact and the remainder of the upper generatrix of the tube (Figure 9).

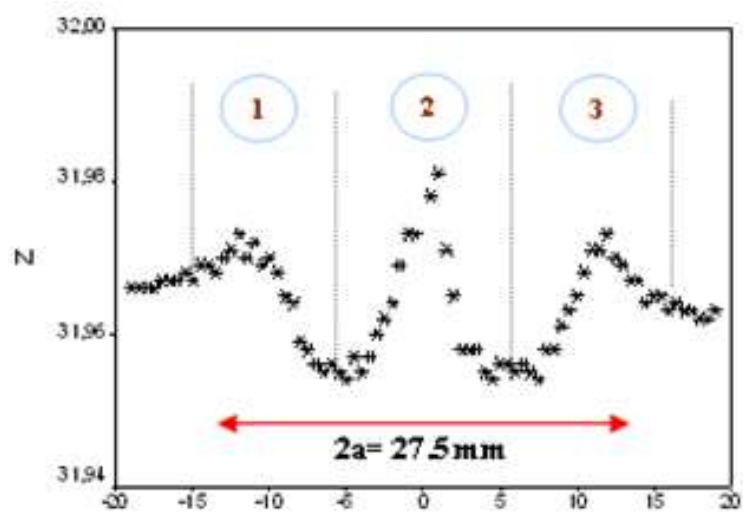

(a)

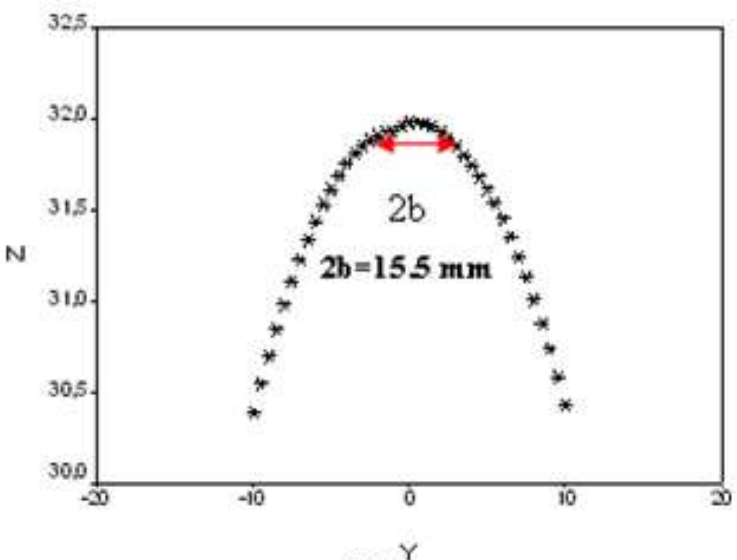

(b)

Figure 9: 2D graphic representation (small scale) of certain series of measurement points of the probe, (a) Graphic representation of the measurement points scanned only over the length $(x, z)$, (b) Graphical representation of the measurement points scanned only over the width $(\mathrm{y}, \mathrm{z})$.

Domains 1, 2 and 3 identified in Figure 9 are attributed to the adhesion between the striker and the polymer material during impact. The curvature of the tube makes it more difficult to measure the " $b$ " dimension using the TMM. Areas (in $\mathrm{mm}^{2}$ ) of the impacted zones are summarized in Table 2, for all the impact tests.

\subsection{Examination of tensile tests results}

The experimental results from measurements performed by MMT and the tensile test machine are summarized in Table 2: Area of the affected zone $\left(\mathrm{S}_{\mathrm{i}}\right)$, and the residual ultimate tensile stress $\left(\sigma_{\mathrm{yr}}\right)$.

Table 2: Values of the dimensions measured in the area of the impact zone $\left(\mathrm{S}_{\mathrm{i}}\right)$ and residual ultimate stress $\left(\sigma_{\mathrm{yr}}\right)$.

\begin{tabular}{l|l|l|l|l|l|l}
\hline $\begin{array}{c}\text { DESIGNATION : } \\
\mathbf{H} / \mathbf{M}\end{array}$ & $\begin{array}{c}\mathbf{M} \\
\mathbf{( K g})\end{array}$ & $\begin{array}{c}\mathbf{h} \\
(\mathbf{m})\end{array}$ & $\mathrm{E}_{\mathrm{C}(\mathrm{HI})(\mathrm{J})}$ & $\boldsymbol{\beta}=\mathrm{E}_{\mathrm{C}(\mathrm{H})} / \mathrm{E}_{\mathrm{C}(\mathrm{HMAX})}$ & $\begin{array}{c}\mathbf{S}_{\mathrm{I}} \\
\mathbf{m m}^{2}\end{array}$ & $\sigma_{\mathrm{YR}}(\mathrm{MPA})$ \\
\hline $0 / 16 \mathrm{~kg}$ & 16 & 0 & 0 & 0 & 0 & $\sigma_{0}=51.4$ \\
\hline
\end{tabular}


CHRISTIAN, F. B.; BIENVENU, K.; KHALIFA , M.; THEODORE, T.; MEDARD, F., LUCIEN, M. revista Matéria, v. 21, n. 01, pp. $83-91,2016$.

\begin{tabular}{l|l|l|l|l|l|l}
\hline $0.2 \mathrm{~m} / 16 \mathrm{~kg}$ & 16 & 0.2 & 18 & 0.07 & 157.0 & 51.1 \\
\hline $0.5 \mathrm{~m} / 16 \mathrm{~kg}$ & 16 & 0.5 & 65.4 & 0.25 & 265.0 & 49.2 \\
\hline $1 \mathrm{~m} / 16 \mathrm{~kg}$ & 16 & 1 & 145.8 & 0.56 & 306.3 & 47.0 \\
\hline $1.25 \mathrm{~m} / 16 \mathrm{~kg}$ & 16 & 1.25 & 182.7 & 0.71 & 334.7 & 45.7 \\
\hline $1.5 \mathrm{~m} / 16 \mathrm{~kg}$ & 16 & 1.5 & 225.5 & 0.88 & 375.8 & 44.2 \\
\hline $1.7 \mathrm{~m} / 16 \mathrm{~kg}$ & 16 & hmax $\geq 1.7$ & 254.4 & 0.99 & 438.2 & 41.1 \\
\hline
\end{tabular}

M: mass of the striker,

$\mathrm{H}$ : height of release of the striker

$\mathrm{E}_{\mathrm{c}(\mathrm{hi})=} \mathrm{MV}^{2} / 2$ : kinetic energy of falling mass,

$\mathrm{Si}$ : area of the affected zone,

$\sigma_{\mathrm{yr}}$ : residual ultimate stress

By analogy to the fraction of fatigue life $[6,7]$, we define the dimensionless parameter $\beta$ as the impact energy at any height $h$, relative to maximum impact energy causing fracture with a corresponding height $h_{\max }$ (table 2): $\beta=\mathrm{Ec}(\mathrm{hi}) / \mathrm{Ec}(\mathrm{hmax})$.

The evolutions of the area of the affected zone and of the tensile stress elastic limit $\sigma_{\mathrm{yr}}$ according to $\mathrm{b}$ are shown in Figure 10.

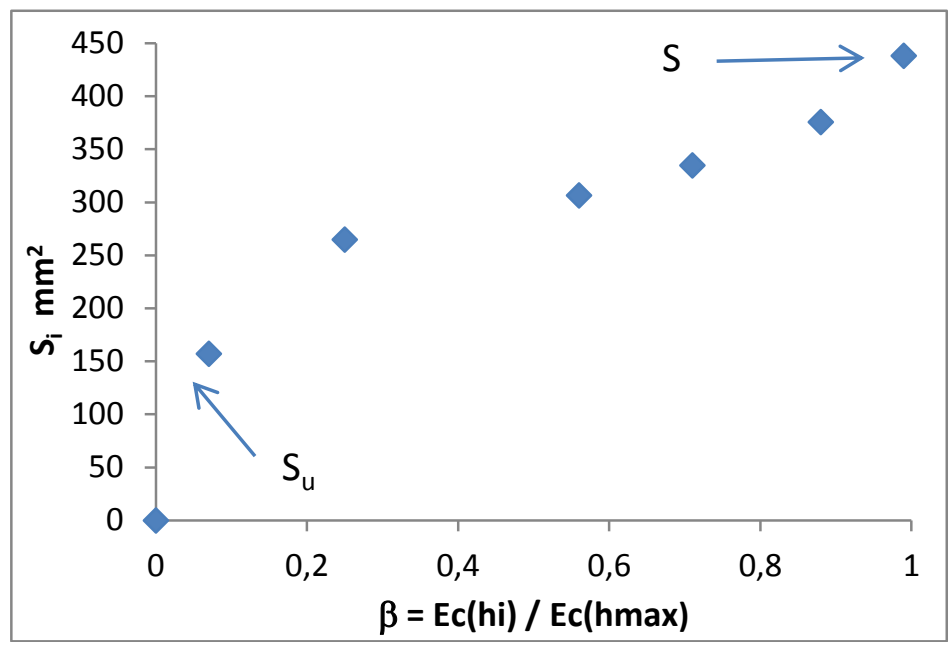

(a)

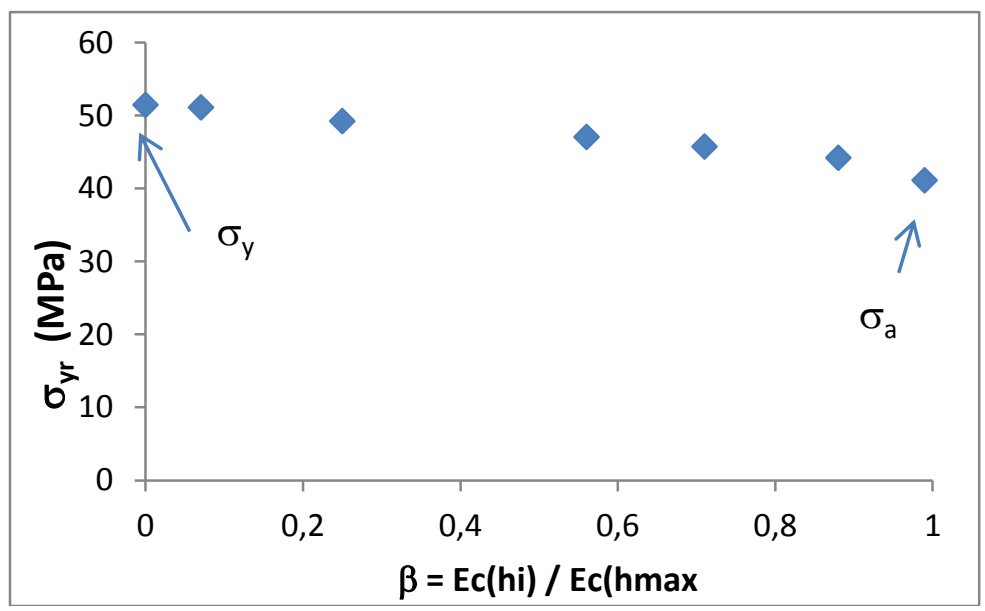

(b)

Figure 10: Evolution based on the level of impact suffered $\beta$ : (a) the area of the affected zone " $\mathrm{S}_{\mathrm{i}}$ " and (b) the residual ultimate stress " $\sigma_{\mathrm{yr}}$ ". 
From Figure 10, it is found that the curve of the residual ultimate stress changes in a manner opposite direction to that of the area of the impact zone. Indeed, the stress $\sigma_{\mathrm{yr}}$ decreases by $51.4 \mathrm{MPa}$ (virgin material: not affected) for $\beta=0$, to $41.1 \mathrm{MPa}$ value for $\beta=1$ (representing the rupture during the impact test). While the area of the affected zone increases gradually from zero (not impacted tube) to a maximum value of 438.2 $\mathrm{mm}^{2}$ measured before fracture due to impact. This divergence between the area of the affected zone, and loss of strength of the material can be explained from the observation of the impacted area (Figure 11).

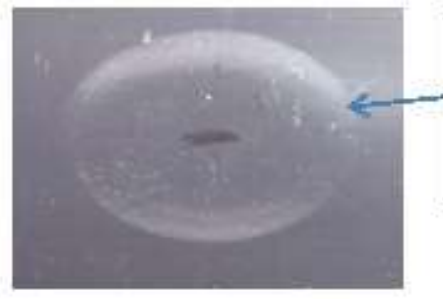

(a) $\mathrm{m}=16 \mathrm{~kg}, \mathrm{~h}=\mathbf{0 . 5 \mathrm { m }}$

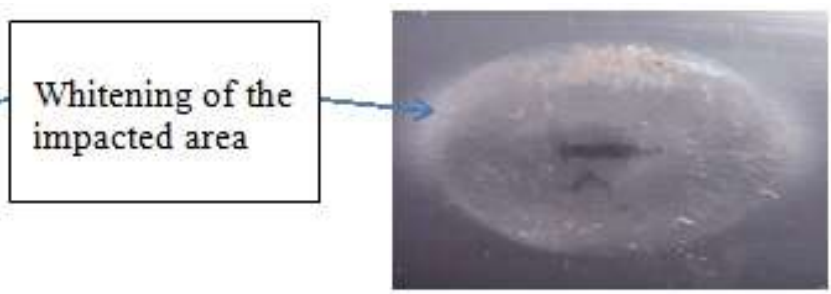

(b) $\mathrm{m}=16 \mathrm{~kg}, \mathrm{~h}=1 \mathrm{~m}$

Figure 11: Photographs of the affected area of the pipe section for different heights of the released firing pin.

Note in these photographs, the area of the affected zone is completely bleached. In literatures on amorphous polymers, bleaching allows the macroscopic localization of microscopic damage phenomena [8, 9]; recent studies have confirmed that bleaching was linked to the appearance of microscopic defects in the polymer structure [10]: cracks, cavities etc. It is therefore clear that the extent of the area of the impact zone determines to a certain proportion the morphological damage caused by the impact. The damage caused is detected by the loss of mechanical properties in this study. The evolution of the residual ultimate stress versus the area of the affected zone, is represented in Figure 12.

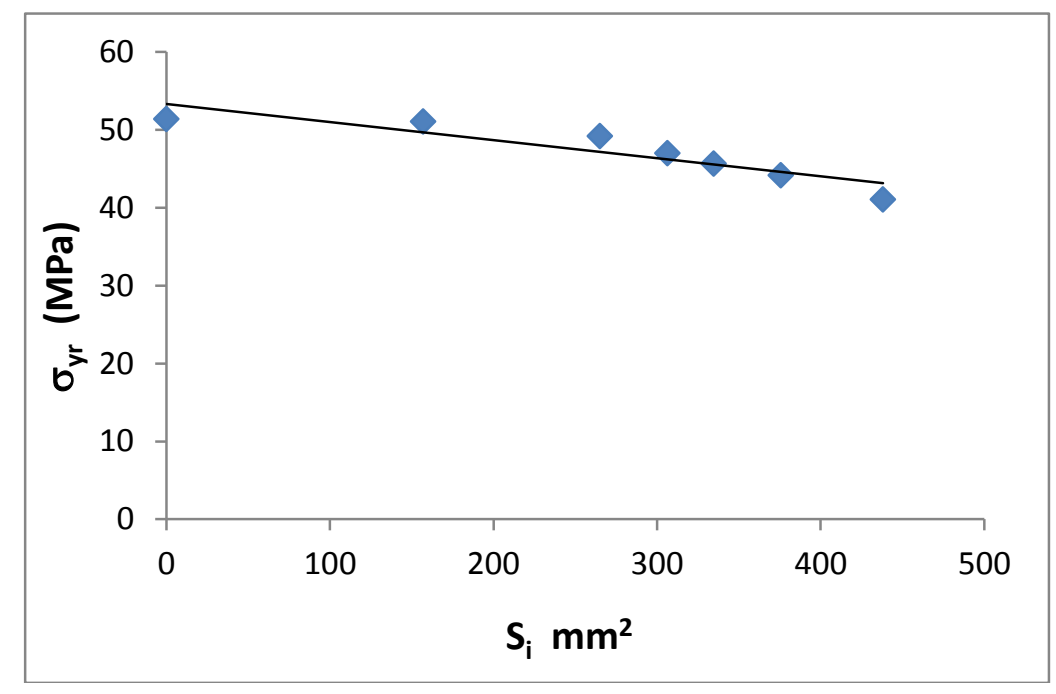

Figure 12: Evolution of the ultimate residual stress as a function of the size of the affected zone.

Note in Figure 12, the residual ultimate stress can be linearly correlated to the area of the impacted area. This correlation shows that the area of the impact zone is also a size capable of realizing the damage caused by the impact (relative to the size of the tip of the firing pin).

\section{DAMAGE EVALUATION}

The loss of resistance of a material, following any mechanical stress, refers macroscopically to degradation or activation of a damaging mechanism (at the micro scale) in the structure. Within the literature on the subject matter, it is found that damage models are coupled with the measured residual resistance [3, 4]. Generally, damage is defined as the phenomenon which refers to the gradual deterioration or microstructural modification which alters the macroscopic mechanical properties of a material [3, 4].

During the development of the unified theory, Bui Quoc et al [11,12] proposed a formulation of the experimental damage (normalized damage) coupled to a conventional mechanical property: ultimate stress 
(Equation 1).

$$
D_{E x p}=\frac{1-\frac{\sigma_{y r}}{\sigma_{y}}}{1-\frac{\sigma_{a}}{\sigma_{y}}}
$$

Where

$\sigma_{\mathrm{yr}}$ : residual ultimate stress for any level of impact,

$\sigma_{\mathrm{y}}$ : ultimate stress of virgin material $\left(\sigma_{\mathrm{y}}=51.49 \mathrm{MPa}\right)$,

$\sigma_{\mathrm{a}}$ : critical residual ultimate stress $\beta=1$ (Figure $10 \mathrm{~b}$ ).

The correlation established in Figure 12, allows to consider the area of the affected zone as a macroscopic property characterizing the damage caused by the impact. By analogy to the damage model of equation (1), a formulation of damage combined with the area of the impact zone $\left(\mathrm{S}_{\mathrm{i}}\right)$ : is proposed.

$$
D_{S e l}=\left(\frac{1-\frac{s_{i}}{S_{u}}}{1-\frac{S_{a}}{S_{u}}}\right)^{\alpha}
$$

Where

$S_{\mathrm{i}}$ : the area of the impact zone measuring any impact,

$\mathrm{S}_{\mathrm{u}}$ : the minimum area below which no loss of strength is observed, it characterizes in a certain way the virgin material (figure 10a),

$\mathrm{S}_{\mathrm{a}}$ : critical area beyond which the tube breaks during impact, $\beta=1$ (Figure 10a),

$\alpha$ : correlation coefficient $(\alpha=2)$.

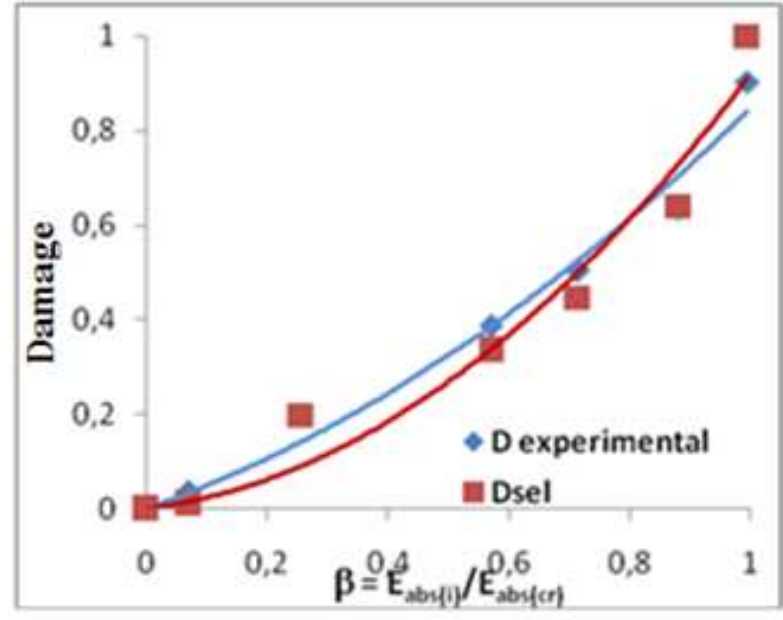

(a)

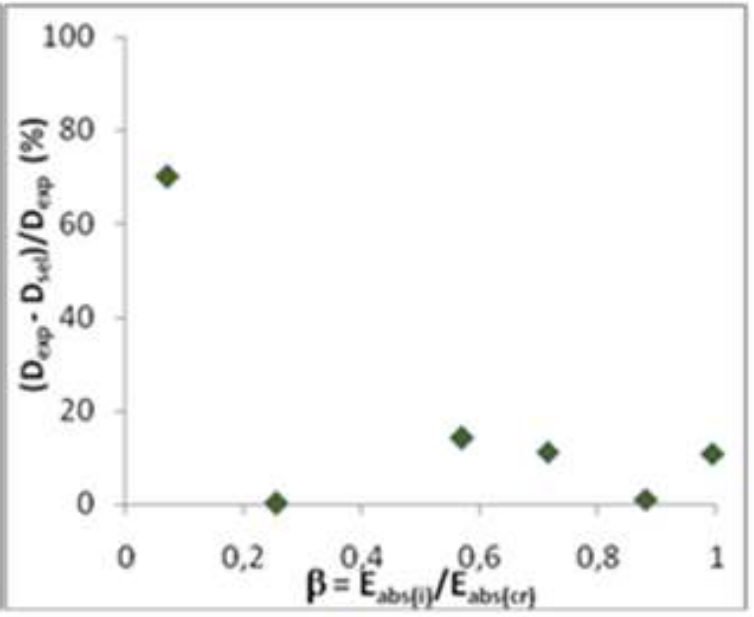

(b)

Figure 13: (a) Comparative evolution of the damage $D_{\exp }$ and $D_{\text {sel }}$ for $\alpha=2$. (b) Differences arising between the curves $D_{\text {exp }}$ and $D_{\text {sel }}$.

In Figure 13, the experimental damage of $D_{\exp }$ gradually rises from $\mathrm{D}=0$ (undamaged material) to a value $\mathrm{D}=1$ (completely damaged material). The $\mathrm{D}_{\text {Sel }}$ damage (with $\alpha=2$ ) correctly reproduces qualitatively the $D_{\exp }$ damage. However quantitatively for $\beta \leq 0.7$, the $D_{\text {sel }}$ damage underestimates the damage level and beyond $\beta>0.7$, the $D_{\text {sel }}$ damage slightly overestimates the level of damage. Except for $\beta \leq 0.25$ with the relative deviations of the order of $\pm 85 \%$, the $D_{\text {sel }}$ estimates are sufficiently close to $D_{\exp }$ quantitatively and the relative differences are of the order of $\pm 15 \%$.

Despite the relatively high gaps for low values of $\beta, D_{\text {sel }}$ damage predictions are considered satisfactory if one wishes to determine the critical damage leading to collapse of the structure (which corresponds to $\beta$ beyond 0.25 for polymeric materials). 


\section{CONCLUSIONS}

In this article, a study on the assessment of the damage on rigid PVC tubes (Polyvinyl chloride) subjected to a quasi-static type of impact was conducted. This study is heavily dependent on testing and measuring impacts of residual tensile properties.

Impact tests using a $16 \mathrm{~kg}$ mass dropped from different heights, have enabled the observation of bleaching of the area of the affected zone (whose dimensions depend on the level of impact). Tensile tests performed later on specimens collected from the affected zone of the tubes showed a loss of material strength. Thus, it was evaluated the level of damage of the material through the Bui Quoc model (damage coupled with the ultimate residual stress). By analogy to the expression of the damage obtained by Bui Quoc, a formulation of damage combined with the area of the impact zone was proposed. Having thus defined the damage, its comparison with that of Bui Quoc qualitatively shows good agreement, as well as quantitatively for $\beta \geq 0.25$.

\section{BIBLIOGRAPHY}

[1] DIOP, M., Le partenariat public-privé: une alternative à l'aide publique au développement? L'exemple des services urbains d'eau au Sénégal, Mondes en développement 1, n. 165 , pp. 79-92, 2014.

[2] LARGE, A., LE GAT, Y., ELACHACHI, S.M., Optimisation du renouvellement des canalisations d'eau potable : méthodes à long terme et à court terme, In : 32èmes Rencontres de l'Association Universitaires de Génie Civil (AUGC), pp. 11, Orléans, France, 2014.

[3] LEMAITRE, J., CHABOCHE, J.L., Mécanique des Matériaux Solides, Paris, Dunod, 1996.

[4] YASUHIRO, S., Effet d'une pré-déformation sur l'endommagement anisotrope d'un acier pour pipeline de grade API X100, Thèse, Ecole Nationale Supérieure des Mines, Paris, France, 2014.

[5] YAO, Y., XU, H., et al, "A continuum damage mechanics-based unified creep and plasticity model for solder materials”, Acta Materialia, v. 83, pp. 160-168, 2015.

[6] HANS-HENNING, K., Matériaux Polymères: Propriétés Mécaniques et Physiques, v.14 de Traité des matériaux, PPUR presses polytechniques, 2001.

[7] MANEL, B., Etude de l'endommagement et du comportement en fatigue des aciers à outils. Thèse, Ecole nationale des Mines d'Albi-Carmaux, Toulouse, France, 2014.

[8] ESTEVEZ, R., VAN DER GIESSEN, E., "Modelling and computational analysis of fracture of glassy polymers", Advances in Polymer Science, v. 188, pp 195-234, 2005.

[9] HEYDEN, S., KWEINBERG, BLI, and al, "A micromechanical damage and fracture model for polymers based on fractional strain-gradient elasticity", Journal of the Mechanics and Physics of Solids, v. 74, pp.

175-195, 2015.

[10] GEARING, B.P., ANAND, L., “On modelling the deformation and fracture response of glassy polymers due to shear yielding and crazing”, International Journal of Solids and Structures, v. 41, pp. 3125-3150, 2004.

[11] QUOC, T, B., DUBUC, J., BAZERGUI, A. "Cumulative fatigue damage under strain controlled condition", Journal of Material, pp. 718-737, 1986.

[12] RON, Y., HAIQUING, L., HUANG, H.A., et al, “A nonlinear fatigue damage accumulation model considering strength degradation and its applications to fatigue reliability analysis", International Journal of Damage Mechanics, v. 23, n.5, pp. 609-726, 2014. 